
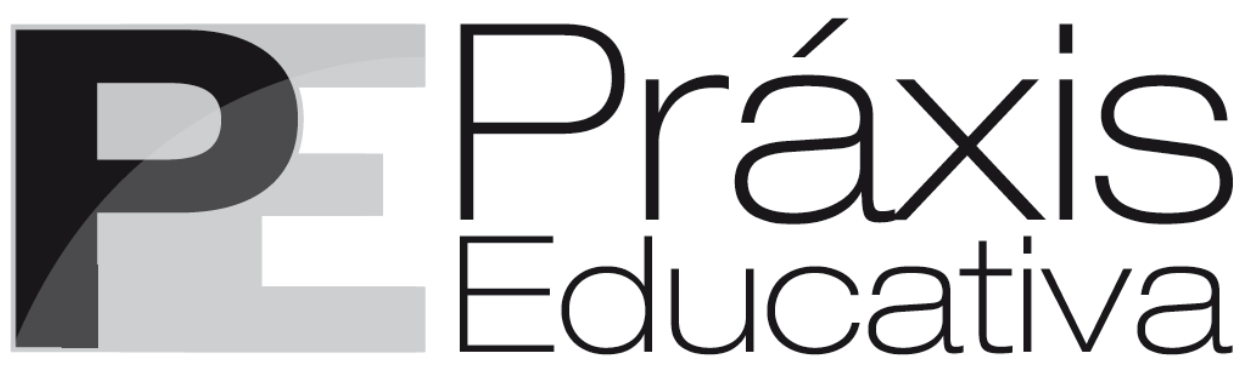

ISSN 1809-4031

elSSN 1809-4309

https://doi.org/10.5212/PraxEduc.v.15.16482.090

\title{
La escuela en la pandemia. Reflexiones sobre lo escolar en tiempos dislocados
}

\section{A escola na pandemia: reflexões sobre o escolar em tempos deslocados}

\section{The school in the pandemic: reflections on schooling in dislocated times}

Inés Dussel*

https://orcid.org/0000-0003-3983-3985

\begin{abstract}
Resumen: La pandemia ha cambiado la "domiciliación” de lo escolar, trasladándola hacia el espacio doméstico. Este artículo se pregunta por los efectos de esta domestización de las escuelas, particularmente cuando se la considera en su intersección con las desigualdades preexistentes y con las tecnologías y las pedagogías disponibles. El argumento central es que, de manera contraria a lo que sostienen los argumentos tecnofílicos, estos cambios introducen numerosas tensiones difíciles de resolver, y permiten ver la relevancia de la estructura material y simbólica de la escuela para producir un espacio otro que haga lugar a una autonomía intelectual y afectiva progresiva. También se presenta la idea de que la clase es un entorno socio-técnico particular que habilita formas de trabajo con los saberes, a la par que organiza a los cuerpos y los tiempos en actividades que deberían proponer desafíos intelectuales; esto está desacomodado en los arreglos educativos improvisados en la emergencia, que muestran un desplazamiento de los énfasis y jerarquías del trabajo escolar. En la parte final, se esbozan claves para debatir algunos de los aprendizajes de estos tiempos dislocados.
\end{abstract}

Palabras clave: Pandemia. Escuelas. Clases. Entorno-socio técnico. Desigualdades.

Resumo: A pandemia tem mudado a "domiciliação" do escolar, transladando-a para o espaço doméstico. Este artigo questiona sobre os efeitos dessa domestização das escolas, particularmente quando ela é considerada em sua intersecção com as desigualdades pré-existentes e com as tecnologias e as pedagogias disponíveis. O argumento central é que, de maneira contrária ao que afirmam os argumentos tecnofílicos, essas mudanças introduzem numerosas tensões difíceis de resolver, e permitem ver a relevância da estrutura material e simbólica da escola para produzir um espaço outro que dê lugar a uma autonomia intelectual e afetiva progressiva. Também é apresentada a ideia de que a sala de aula é um entorno sociotécnico particular que habilita formas de trabalho com os saberes, ao tempo que organiza os corpos e os tempos em atividades que propõem desafios intelectuais; isso está desalinhado nos arranjos educacionais improvisados na emergência, que mostram um deslocamento

\footnotetext{
* Investigadora Titular - Departamento de Investigaciones Educativas del Centro de Investigación y Estudios Avanzados (DIE-CINVESTAV), México. Miembro del Sistema Nacional de Investigadores, Nivel III. E-mail: <idussel@gmail.com>.
} 
da ênfase e hierarquias do trabalho escolar. Na parte final, esboçam-se chaves para debater alguns dos aprendizados desses tempos deslocados.

Palavras-chave: Pandemia. Escolas. Salas de aula. Entorno sociotécnico. Desigualdades.

Abstract: The pandemic has changed the "domiciliation" of schooling, bringing it into the domestic space. This article questions the effects of the "domestization" of schools, particularly when it is considered at its intersection with pre-existing inequalities and with available technologies and pedagogies. The central argument is that, contrary to what the technophilic arguments state, these changes introduce numerous tensions that are difficult to resolve, and show the relevance of the material and symbolic structure of the school to produce an other space that gives rise to a progressive intellectual and affective autonomy. It is also argued that the classroom is a particular socio-technical environment that enables ways of working with knowledge while organizing bodies and times in activities that should pose intellectual challenges; this is misaligned in the improvised educational arrangements in the emergency, which show a shift in emphasis and hierarchies of the school work. In the final part, keys are outlined to discuss some of the lessons learned from these dislocated times.

Keywords: Pandemic. Schools. Classrooms. Socio-technical environment. Inequalities.

\section{Introducción}

Lenin, el revolucionario ruso, decía que hay décadas en las que no pasa nada y semanas en las que pasan décadas. ${ }^{1}$ Sin duda estamos en esas semanas -ya meses- en las que la historia parece acelerarse, y muchas cosas que no parecían posibles se realizan: detener la economía, los aviones, la circulación de autos, los encuentros masivos, la virtualización de la educación o a veces la parálisis casi total de la educación.

La transición fue abrupta y las políticas educativas fueron muy variables. Buena parte de los países latinoamericanos suspendieron las clases e implementaron programas para mantener la escuela o la universidad "a distancia", ya sea a través de plataformas digitales, televisión, radio, o por medio de materiales impresos (QUEZADA, 2020).

Para algunos, este escenario anticipa lo que será la educación del futuro, de aprendizajes ubicuos, sin espacios escolares específicos y sin tiempos programados ("justo-a-medida" del usuario). Se dice que el futuro es hoy, que hoy comienza el nuevo paradigma que demostrará que la escuela es una institución obsoleta y los maestros son obstáculos en el acceso directo de niños y jóvenes al conocimiento. Se habla de un experimento a escala mundial que demostrará, por fin, las ventajas del aprendizaje en línea (ZIMMERMAN, 2020).

Pero están quienes tienen la visión opuesta. Para ellos este es un escenario distópico, parecido al sálvese quien pueda, que llevará a la pérdida de la dimensión pública y común de la escolarización. Un ejemplo radical de esta postura fue el ensayo de Giorgio Agamben, quien escribió un "Requiem por los estudiantes" convencido de que las pantallas acabarán con el estudiantado como forma de vida por la pérdida de los encuentros y el intercambio asiduo. El italiano incluso habló de una "dictadura telemática", similar al régimen fascista (AGAMBEN, 2020).

No hay dudas de que el contexto actual presenta una suerte de experimentación a gran escala de estas hipótesis. Está claro que lo que está ocurriendo no es la mejor versión de la educación virtual, sino que se compone de distintos "arreglos institucionales" para seguir ofreciendo educación a

${ }^{1}$ La cita es de Lenin, Las principales tareas de nuestro tiempo (marzo de 1918), citado en Sebestyen (2020), p. 5.

Práxis Educativa, Ponta Grossa, v. 15, 2016482, p. 1-16, 2020

Disponível em: <https://www.revistas2.uepg.br/index.php/praxiseducativa> 
distancia en un contexto de emergencia (HODGES et al, 2020). Pero lo que se organiza con esta educación remota es bastante distinto a lo que imaginaban quienes celebran la difusión de las tecnologías y el reemplazo de las escuelas. Un primer rasgo, tan doloroso como previsible, son las desigualdades de conexión, que profundizan las desigualdades ya existentes en distintas sociedades del mundo, no solamente en América Latina. La pandemia pone de manifiesto que unos acceden a plataformas con mucha oferta y acompañamiento sostenido y otros tienen que arreglárselas con pocos impresos o charlas por whatsapp, si es que acceden, de manera parecida a como antes accedían a circuitos de distinta calidad educativa. Un segundo rasgo de esta educación remota de emergencia, quizás menos pasible de anticiparse, es que se puede ver las plataformas permiten menos de lo que se prometía, tanto por las limitaciones técnicas actuales como porque -y aquí quizás puede dársele algo de crédito al pesimismo de Agamben- dificultan algunas de las acciones básicas que constituyen lo escolar, al menos tal como lo conocemos.

Probablemente sea este último punto el que resulta más interesante para pensar estos tiempos dislocados, out of joint, una expresión de Shakespeare que Derrida recupera magistralmente en Espectros de Marx (1992): un tiempo de esperas, rodeado de espectros, de lo que ya no es pero tampoco termina de ser. ${ }^{2}$

En este artículo, me interesa mirar especialmente la transformación de lo escolar a partir de este traslado de la actividad a las casas para analizar los cambios que implica esta nueva "domiciliación" de la escuela, ya no en "sede edilicia escolar" sino instalada en lo doméstico, y sobre todo en las pantallas. Tomo la idea de "domiciliación" del trabajo de Derrida sobre los archivos (1997a), en el que el filósofo francés discute las implicaciones de la asignación de los documentos de la memoria a un lugar fijo, que impone formas particulares formas de producir filiaciones a las instituciones y a la cultura común. Derrida analiza cómo se instaura una autoridad, la de los arkhontes, que guardan la memoria y actúan también como "porteros", reguladores de la circulación.

El análisis derridiano es sugerente para pensar las transformaciones de la cultura común y de los conocimientos cuando se los asigna a un espacio particular, el de la escuela, con sus autoridades, sus reglas y modos de operación: ¿qué se produce en esa domiciliación a una institución particular? Mucho se ha discutido sobre esto, y en América Latina ha sido fuerte la impugnación a la parcelación y fragmentación que supone confinar los conocimientos a un único lugar legítimo, así como la crítica a la desjerarquización y colonización de otras formas, por ejemplo populares e indígenas, que introdujo la escuela moderna (PINEAU, 2001). Otras perspectivas críticas más recientes, vinculadas a la expansión de los medios digitales, propusieron la idea de "aprendizajes ubicuos" para dar cuenta de la importancia de muchos saberes que circulan en ámbitos no escolares (BURBULES, 2009). Ambas críticas suponen que algo bueno sucederá cuando se derrumbe la jerarquización escolar y cuando se termine de abrir la escuela a otras culturas y saberes.

Sin embargo, lo que está sucediendo parece abrir otra serie de preguntas e inquietudes, que permiten poner en cuestión algunas de las críticas formuladas. ¿Qué pasa con la mudanza o domiciliación de la escuela en el espacio doméstico? ¿Qué sucede con la pérdida de la diferenciación de espacios, roles, identidades, reglas propias de la escuela y su súbita reacomodación a las cocinas, los cuartos, las salas, los baños? ¿Qué nuevas reglas y autoridades se instalan? ¿Qué posibilidades de

${ }^{2}$ La idea de tiempos dislocados la desarrollamos con Darío Pulfer y Patricia Ferrante en un libro de próxima aparición (DUSSEL, FERRANTE, PULFER, en prensa). Agradezco a estos dos colegas las productivas charlas en las que estos argumentos fueron cobrando forma.

Práxis Educativa, Ponta Grossa, v. 15, 2016482, p. 1-16, 2020

Disponível em: <https://www.revistas2.uepg.br/index.php/praxiseducativa $>$ 
filiación a los saberes se abren, y cuáles se desorganizan? ¿Qué márgenes para nuevas apropiaciones se inauguran? Un ensayista francés, Christophe Rioux, señaló en los primeros meses de la pandemia que habría que establecer paralelos entre estar confinados en el domicilio y la prisión domiciliaria, cuestión que enlaza con el debate francés sobre la segregación territorial y los nuevos ghettos de la inmigración. Moverse, salirse del domicilio, es, para Rioux y para la tradición republicana francesa, la mejor posibilidad para alcanzar la emancipación intelectual y para construir una sociedad más integrada (RIOUX, 2020). La mudanza a lo doméstico no resultaría, así, en una inversión de las jerarquías socioculturales sino en su reproducción.

La domestización de lo escolar hizo visibles, literalmente, otras cuestiones importantes sobre la escuela. Estar obligados a quedarse en el domicilio supuso también tener que exhibirse como seres domésticos. Una alumna de primaria, preguntada sobre qué aprendió en las primeras semanas, dijo: que mi maestra quiere mucho a los gatos. Esa respuesta puede interpretarse de varias maneras, pero pueden plantearse al menos dos: que esta estudiante no aprendió nada relevante o digno de mención en términos de contenidos escolares, o que le resultó muy sorprendente y memorable conocer la vida privada de su maestra. Sin descartar la primera, habría que inclinarse por la segunda, más reveladora de lo que pasó y continúa pasando. Las familias vieron a sus hijos como alumnos, incluyendo a los propios docentes, que también vieron a sus colegas mucho más de cerca; los hijos tuvieron que ver a sus familias trabajando, con una intimidad que seguramente no habían conocido. Fue común escuchar ruidos de la casa o de la calle e interrupciones inesperadas de hijos o familiares sobre la comida, el mate o el perro.

La reflexión que quiero proponer en este texto, que tiene mucho de notas de campo, de escrituras hechas al calor de lo vivido y permeadas por un clima afectivo particular que combina la sorpresa, la ansiedad y mezclas variables de pesimismo y optimismo, y que se nutrió de conversaciones con colegas de distintas latitudes, ${ }^{3}$ tiene que ver con seguir el hilo de lo que se transforma con la caída del umbral que suponía ir a la escuela como un espacio de trabajo diferenciado. Me interesa rastrear dos aspectos de estas transformaciones: los cambios en la materialidad escolar, sobre todo a partir de la inclusión de las plataformas virtuales y las nuevas configuraciones de espacios-tiempos, y las formas que asume la clase, sus tecnologías y contenidos, que hablan de sus posibilidades de abrir paso a otras filiaciones a la cultura común.

\section{Las transformaciones de la materialidad escolar: las tensiones de la escuela en casa}

La educación es, como dice Jan Masschelein (2014), un asunto que involucra mesas y cavernas: mesas reales o metafóricas sobre las que un grupo de humanos se congrega para trabajar, haciendo de ese trabajo con el conocimiento un asunto público, y cavernas que organizan un "espacio otro" para la educación, una suspensión relativamente al margen de la vida cotidiana. Es interesante notar que las cavernas son espacios importantes en la historia de la educación no solamente por el mito de Platón sino también, y quizás de manera más fundamental, por las pinturas rupestres que pueden considerarse los primeros registros hechos explícitamente para la transmisión de la cultura humana.

\footnotetext{
${ }^{3}$ Además del trabajo ya mencionado con Darío Pulfer y Patricia Ferrante, quiero destacar los encuentros para pensar esta situación con Adriana Fontana y Paola Roldán, particularmente las que dieron origen al conversatorio "La clase en pantuflas", en el Instituto Superior de Estudios Pedagógicos del Ministerio de Educación de Córdoba, Argentina, el 23 de abril de 2020. También las charlas con Jorge Larrosa y Jan Masschelein sobre la escuela y la pedagogía, sostenidas a lo largo de varios años y actualizadas en esta coyuntura que puso a prueba muchos de nuestros supuestos.
}

Práxis Educativa, Ponta Grossa, v. 15, 2016482, p. 1-16, 2020 Disponível em: <https://www.revistas2.uepg.br/index.php/praxiseducativa $>$ 
Metafóricamente, señalan un lugar de protección, de almacenamiento y resguardo, de archivo y transmisión, de imaginación y producción de inscripciones y registros.

Las imágenes que elige Masschelein dejan en claro que el hacer de la educación pasa por la interacción entre seres humanos así como por objetos y espacios que dan forma y contenido a los procesos educativos. La historia de esos espacios en la modernidad fue abordada en un trabajo anterior, La invención del aula. Una genealogía de las formas de enseñar (2000), escrito con Marcelo Caruso, donde sostuvimos que el aula es tanto un espacio material como una estructura comunicativa. En ese trabajo rastreamos la genealogía de cómo se fueron armando espacios definidos para lo escolar que ya no fueron una habitación de una catedral o un cuarto en la casa del maestro: la escuela con sus aulas, separadas de otros usos, con sus tecnologías, su arquitectura, su regulación de los cuerpos (por ejemplo a través de códigos disciplinarios y de los uniformes) con su coreografía (por ejemplo, en el patio se permiten ciertos movimientos y encuentros, en las aulas otros), al mismo tiempo que se planteó una regulación del habla, una ritualización de quién y cómo formula ciertos enunciados (FOUCAULT, 1973).

En aquel momento, prestamos menos atención a algo que hoy es mucho más evidente: la necesidad de considerar esa materialidad desde una noción de técnica o tecnología, y a las escuelas como entornos socio-técnicos, de los objetos y artefactos que se usan en clase. Por entornos sociotécnicos entiendo la conjunción de artefactos y tecnologías con las acciones humanas, como entidades mutuamente imbricadas, en una perspectiva informada por los trabajos de Foucault (1976) y Latour (2005), así como discusiones más recientes (REVEL, 2009; VAN DIJCK, 2016). Las tecnologías, en una visión amplia, pueden ser cualquier invención o artificio creado; designan sobre todo a objetos o artefactos (tenedor, lápiz, rueda, tiza, cuaderno, hasta edificaciones, vestimentas, dispositivos digitales), pero también incluyen tecnologías morales (la confesión) o tecnologías psicológicas (el psicoanálisis), e incluso la voz y el cuerpo pueden ser consideradas como tecnologías en la medida en que son conductos que permiten ciertas experiencias (CASTRO, 2004; sobre los cuadernos de clase, CHARTIER, 2002).

La escuela y la clase han sido siempre entornos socio-técnicos, conformados por esa interacción entre sujetos humanos y espacios, artefactos o tecnologías. El uso del pizarrón, el proyector, la voz o el papel organizan interacciones diferentes. Lo interesante de este momento es que muestra la importancia del edificio escolar, de las cuatro paredes del aula, de las paredes con ventanas, del pizarrón o el proyector como modo de trabajo en común (DUSSEL, 2018); es interesante que se hacen más visibles cuando están ausentes. Pensando en estas tecnologías de la enseñanza, Pablo Pineau escribió sobre lo que significó la introducción de las fotocopias en la educación, sobre todo en la formación superior, donde se impusieron antes que en otros niveles: accesibilidad a libros a los que era imposible acceder, pero también fragmentación, recorte de contenidos (PINEAU, 2020). Lisa Gitelman, una historiadora de la ciencia, investigó la historia de los archivos PDF, otro gran invento con características parecidas a la fotocopia. Los documentos PDF tienen varias ventajas: economizan tiempo y dinero, permiten circular grandes cantidades de información, tienen buscadores avanzados que permiten leer e identificar dentro del texto algunas claves, y herramientas para hacer zoom y centrar la atención. Pero, aún más que las fotocopias, se prestan a la fragmentación del texto en datos; también aplanan las superficies y soportes, borrando signos materiales que permitan identificar rasgos paratextuales que orienten al lector como lo hacen las texturas, los colores o el diseño visible de los 
libros. Otro elemento problemático es que estos archivos separan la lectura y la escritura, y priorizan la lectura antes que la reescritura, reforzando la distinción entre el lector y el escritor. ${ }^{4}$

Las “pedagogías pandémicas” (WILLIAMSON; ENYON; POTTER, 2020) reorganizan a la escuela y el aula en tanto espacios socio-técnicos, y eso tiene efectos concretos en la experiencia escolar que se produce. En este contexto, aparecen varias tensiones que hay que estudiar y mirar de cerca. Quiero referirme a cuatro: la tensión de la forma escolar con las desigualdades, la individualización de las pedagogías en las condiciones socio-técnicas actuales, la falta de alteridad en la domestización de la escuela, y la pérdida de los espacios de conversación.

La primera tensión, obvia y muy conocida por todos, son las enormes desigualdades sociales respecto a la conectividad digital, la comodidad del espacio de trabajo y las posibilidades de las familias de sostener y acompañar los aprendizajes de los chicos. Esta crisis reafirma algo ya sabido, pero no por ello menos importante: la desigualdad en el acceso a las tecnologías digitales es muy grave, y por eso varias de las medidas de política pública han intentado paliarlas, ya sea a través de negociaciones con las compañias celulares para la gratuidad de datos para plataformas educativas, el uso de la televisión o la radio para distribuir contenidos, la distribución de dispositivos digitales, entre otras posibilidades. Entre las cuestiones que quedaron claras con la pandemia es que hay muchos hogares en que, con suerte, hay un solo celular y con datos limitados, cuyo uso se prioriza para la supervivencia diaria. Los docentes se vieron obligados a buscar distintas posibilidades para establecer y sostener conexiones parecidas al aula por los medios que encontraron. Lo que cada uno de esos dispositivos permite es diferente; muchas veces les tocó a los docentes moverse entre plataformas y soportes para seguir los distintos hilos de la clase. La ausencia del espacio físico muestra que, con todas sus dificultades, las aulas organizaban un encuentro en condiciones más igualitarias que lo que permite una infraestructura tecnológica tremendamente desigual.

Una segunda tensión tiene que ver con que la desaparición física de las aulas, en estas condiciones socio-técnicas donde no hay garantizados espacios comunes que permitan interacciones sincrónicas, está generando una mayor individualización del trabajo pedagógico, y este es un aspecto del que se habla menos pero que, de nuevo, revela algo importante. La escuela es un espacio colectivo, un espacio de lo común; para los chicos, la falta del aula presencial produce una ausencia de otras voces infantiles para aprender juntos, que hace que se pierdan algo importante. Algunos chicos, sobre todo los que asisten a escuelas urbanas de clase media y con mucha oferta pedagógica, señalan sentirse saturados de tanta observación y atención adulta puesta sobre ellos; ponen en evidencia que en el aula los chicos se reparten la carga, se escuchan, aprenden de lo que dicen otras u otros, encuentran con quién o en dónde esconderse de la demanda adulta. Los maestros de las escuelas urbanas de clase media manifiestan algo parecido a sus alumnos, en el sentido de que se sienten muy observados por las familias.

\footnotetext{
${ }^{4}$ Eso lleva a decir a Gitelman que el PDF “se siente más reaccionario que revolucionario. [...] Mira hacia atrás, hacia la fijeza de los artefactos impresos analógicos y la división del trabajo entre los impresores y sus clientes lectores, al mismo tiempo que participa de la mitificación de las herramientas digitales para un usuario promedio que queda atrapado en un ambiente 'amigable' donde los usos están parametrizados, limitados a tareas identificadas en un menú, y divididas en herramientas y vistas discretas y separadas" (GITELMAN, 2014, p. 131). Hay actualmente otros programas de lectura de archivos que permiten anotaciones de distintos usuarios y mayores interacciones con el texto; sin embargo, la datificación creciente de todas estas prácticas genera numerosos interrogantes sobre cómo se "codifica" la lectura y se la convierte en otra parte de la maquinaria de mercantilización de las prácticas de saber (VAN DIJCK; POELL, 2018).
}

Práxis Educativa, Ponta Grossa, v. 15, 2016482, p. 1-16, 2020 Disponível em: < https://www.revistas2.uepg.br/index.php/praxiseducativa $>$ 
Esto permite volver a pensar algunas hipótesis sobre la escuela que subrayaron su condición disciplinaria, de encierro y hasta de castigo de la infancia (FOUCAULT, 1976). Pero lo que se ve es que la escuela es también, y quizás sobre todo, un espacio de autonomía, de potencial emancipación de los chicos respecto a sus familias y de las familias respecto a sus hijos (RANCIĖRE, 2009; SIMONS; MASSCHELEIN, 2014). De manera contraria a como se lo pensaba en los años '70, puede observarse que la autonomía se vincula a una característica del confinamiento escolar, que es una menor visibilidad, y que se asienta en una cierta intimidad para el trabajo pedagógico. De pronto, el espacio del aula se volvió muy público, y aunque sin duda esto tiene una parte positiva, porque se viene reclamando desde hace tiempo que la clase tiene que ser pensada como un asunto público (SADOVSKY; LERNER, 2006), hay otra parte que tiene efectos menos auspiciosos, por ejemplo cuando los interlocutores principales de los maestros pasan a ser las familias (otros adultos). Este enunciado no quiere sostener un lugar paidocéntrico ingenuo de "poner en el centro al niño", sino más bien subrayar que la nueva escena pedagógica virtualizada tiene mucho de panóptico, del todo visible, que lejos de convertirla en un asunto público la convierte en un juego de exigencias, de espejos, que desplazan que se está ahí para enseñar y aprender y no para satisfacer al cliente.

Estas escenas pedagógicas en escuelas de clase media, que parecen mostrar cierto exceso de miradas y atención, contrastan con otras de sectores más pobres, donde parece primar la desvinculación y el desenganche (UNICEF-Argentina, 2020). Más que excesos, en estos casos hay ausencias o cortes. Los desafíos son muy distintos en ambos casos, y puede decirse que esas diferencias estaban desde antes de la pandemia, y que las clases ya eran muy distintas en contextos más privilegiados y en contextos con enormes privaciones. Sin embargo, había un mínimo común de reglas, de atención, de señalamientos, que posibilitaban una cierta nivelación de lo que se ofrece. Y sobre todo permitía, a los docentes y directivos comprometidos, otro tipo de trabajo que el que se puede hacer en estas condiciones de educación remota en la emergencia, que suma nuevas exigencias y obstáculos.

La tercera tensión que trae esta dislocación del tiempo y espacio escolar se vincula a la noción de umbral, de pasaje, a la que refería Rioux en su crítica sobre el confinamiento y la segregación en los domicilios y los barrios. Para eso propongo pensar la "domestización" de la escuela desde la noción de "espacios otros" de Foucault. En un texto que originalmente fue una conferencia pronunciada en 1967 en el Círculo de Estudios Arquitectónicos, Foucault hablaba del espacio como un gran lente para mirar la experiencia contemporánea, y formuló la idea de espacios otros, que para él no son las utopías (espacios irreales) sino las heterotopías, emplazamientos reales que contestan o invierten los lugares habituales (internados o colegios, hotel de viajes de boda, servicio militar, cementerio, el cine, el jardín y la alfombra) (FOUCAULT, 1999). En estos espacios otros se juega la heterogeneidad, la posibilidad del pasaje, del umbral, que son importantes para una autonomía intelectual, afectiva, política.

Puede llamar la atención incluir a la escuela en esta serie, porque para el filósofo francés la institución escolar estaba dentro de los ámbitos que organizaban el espacio habitual, es decir, las jerarquías establecidas de poder. Pero en estas nuevas condiciones socio-técnicas, de aprendizajes ubicuos, de la des-especificación de lugares, se pone de manifiesto que los encuadres y las territorialidades, aunque sean digitales, son importantes, y que las escuelas pueden operar como espacios donde se subvierten ciertas jerarquías y, sin duda, se instalan otras. Las escuelas pueden ser pensadas como espacios otros si acordamos que conocer, como dice Chantal Maillard, implica merodear por lo ajeno, exraviarse, alejarse, irse lejos y volver para producir una "re-flexión sobre lo propio. [...] De no ser así, habremos hecho lo que cualquier turista: ir de lo mismo a lo mismo, salir de lo propio no tanto para desestabilizarlo como para reforzarlo por medio de lo otro" (MAILLARD, 2014, p. 13).

Práxis Educativa, Ponta Grossa, v. 15, 2016482, p. 1-16, 2020 Disponível em: <https://www.revistas2.uepg.br/index.php/praxiseducativa $>$ 
En esta época de plataformas "homofílicas", de los filtros de burbujas y "ecoho-chambers" que nos hacen ir "de lo mismo a lo mismo" (CHUN, 2018), la escuela puede operar como un espacio otro que ayude a animarse a ese merodeo por lo ajeno, por lo de otros y lo de todos, para volver a pensarse a sí mismo con otras herramientas. Es precisamente su condición de entorno socio-técnico no prioritariamente digital lo que promueve y habilita otro tipo de interacciones.

Para pensar en lo que generan las escuelas como espacios otros, quiero dialogar con la hipótesis de los filósofos belgas Jan Masschelein y Maarten Simons de la escuela como suspensión (SIMONS; MASSCHELEIN, 2014), de la escuela que se quiere suspender de la vida cotidiana, como una condición para que pueda hacer un cierto tipo de trabajo, de estudio, que es también una condición de igualdad en la que los sujetos puedan ser simplemente estudiantes o docentes, y no solamente hijos de, hermanos de otros.

Las clases suspendidas impiden que la escuela opere como suspensión del afuera, porque ya no es un afuera sino que se confunde con lo doméstico. Ese 'borramiento' de fronteras entre la escuela y la casa trae varios problemas, difíciles de solucionar en estas condiciones: las familias se ven obligadas a asumir tareas que pueden confundir y complicar los vínculos (visible en las peleas de los padres con los hijos para que hagan la tarea), y los chicos pierden la posibilidad de un tiempo autónomo y de construir redes de conocimiento y afectivas fuera de su núcleo familiar, ya sean maestros o compañeros, de manera sostenida, que es también una forma de lograr una creciente autonomía política, esto es, de las relaciones de poder en la familia y en la sociedad. Tampoco es bueno para los maestros: dar clase en estas condiciones (para muchos, no para todos, ya que hay quienes desisten, tanto como hay chicos que desisten) implica a veces trabajar doce, quince horas por día, tener que explicitarlo todo, armar recorridos con soportes más desafiantes, sentirse siempre evaluados. Son tiempos extenuantes, de conexión permanente, intensificación del trabajo, agotamiento constante.

Finalmente, quiero señalar una cuarta tensión: la dificultad para recuperar lo propio de la vida del aula en las actuales condiciones tecnológicas, atravesadas por la desigualdad pero también por lo que las plataformas permiten y/o dificultan. Cualquiera que haya hecho alguna clase con un grupo grande en las plataformas que tenemos disponibles sabe que son mejores para dar conferencias o charlar con amigos, y son peores para conversar en grupo, seguir hilos de pensamiento más singulares y disponerse a trabajar entre todos. Pero el punto central es que, aún cuando las plataformas mejoren y tengamos esas opciones en la plataforma, seguiremos necesitando que haya maestras y maestros que se preocupen por generar y acompañar ciertos procesos de aprendizaje en sus alumnos, de manera colectiva pero también singular, porque el aula se organiza pedagógicamente en torno a un trabajo en común pero también de cada uno. Da la impresión de que para lograr ese tipo de trabajo que sea simultáneamente para todos y para cada uno, hay todavía grandes ventajas en trabajar en un espacio físico donde se ven las caras, donde los maestros pueden seguir las miradas y cambiar de ritmo o de foco porque se percatan de las señales, no siempre verbales, que indican que algo no está funcionando del todo bien, y donde se pueden generar formas de atención enfocadas en algún asunto sin tantas distracciones como en casa. La clase es un espacio-tiempo multisensorial, pero las tecnologías digitales a veces privilegian lo escrito por sobre otras interacciones, aunque también se está viendo en muchas escuelas una creciente oralización de la enseñanza, algo sobre lo que me detengo más abajo. Para las plataformas escolares más utilizadas (Padlet, Classroom) la multimodalidad -el uso de múltiples modos de comunicación (oral, escrito, visual, gestual)- no es fácil de resolver, y menos aún la sincronicidad. Aún en las escuelas privadas con muchos recursos disponibles se organizan en turnos para que los grupos escolares puedan encontrarse dos o tres veces a la semana.

Práxis Educativa, Ponta Grossa, v. 15, 2016482, p. 1-16, 2020 Disponível em: <https://www.revistas2.uepg.br/index.php/praxiseducativa $>$ 
Pero el límite no es solamente el de la capacidad de las plataformas sino el de la atención, que es otro gran tema pedagógico. ¿Quién puede quedarse en una reunión sincrónica tres horas seguidas, con tanta demanda incesante? Este confinamiento hace visibles los problemas de la nueva economía de la atención (la atención como mercancía, como bien comercializable: venden segundos o minutos de nuestra atención en los avisos de internet) con plataformas que mandan continuamente estímulos para capturar al público por un buen rato, y que generan una atención flotante, siempre disponible para la nueva interrupción. En esta nueva economía de la atención, es difícil concentrarse en algo (DUSSEL, 2020). Y si en la escuela concentrarse en el estudio ya era difícil, en el ámbito doméstico lo es mucho más. Aquí cobran otra dimensión las interrupciones continuas de lo doméstico en las clases o reuniones referidas al principio: ya no son solamente anécdotas, sino evidencias de un problema mayúsculo para las pedagogías en estas condiciones socio-técnicas. Queda claro que los nuevos espacio-tiempos de lo digital son muy desafiantes para ciertas formas de trabajo con los saberes, $\mathrm{y}$ también que probablemente sean menos liberadores de lo que prometía la crítica anti-escolar, que veía en la exploración y navegación libres de las plataformas una emancipación respecto a la fijeza de lo escolar. Sin embargo, esta crítica se olvidaba de las nuevas sujeciones que trae la conectividad permanente y la invasión cada vez mayor de todos los ámbitos de la vida social por las plataformas (VAN DIJCK, 2016). En la pandemia, nos reconocemos cada vez más esclavos de las redes y atados a los celulares, y se redescubre el valor de la desconexión y la libertad que ella trae, sobre todo cuando es por decisión propia.

\section{Formas y contenidos de la clase en la pandemia}

¿Cómo cambian los contenidos de la escuela con esta nueva situación?¿Qué lenguajes y qué tipo de actividad habría que privilegiar? ¿Qué formas toma en este contexto de educación remota en condiciones tan desiguales? En relación con la primera pregunta, hay un debate entre los especialistas sobre si la escuela tiene que seguir enseñando el programa ya establecido (los continuistas), o si tiene que adaptar sus contenidos a lo que está sucediendo. Francesco Tonucci decía, en una entrevista reciente en El País, que habría que seguir la segunda línea: hacer de esta experiencia una oportunidad de aprender sobre el mundo, sobre la organización del trabajo doméstico, entre otros aspectos, pero no como lecciones sino como una transmisión que ocurre mientras se cocina y se limpia la casa o se escuchan las noticias (TONUCCI, 2020). Tonucci tiene razón en la importancia de abrir proyectos de conocimiento sobre esta crisis, y en recordar que los saberes valiosos no se reducen al programa escolar.

Será necesario, en este tiempo, documentar mejor qué representó la continuidad pedagógica en las escuelas. Lo que se pudo observar es que en las primeras semanas de la emergencia hubo una tendencia a distribuir tareas, con la intención de ocupar la jornada infantil y, también, protegerse de posibles críticas a la desatención docente. Había una demanda de llenar el tiempo, de hacerse presentes en el marco de una situación inédita y dramática, y de no perder el año ni la continuidad de los programas. Pero esa profusión de tareas generó agotamiento, y sobre todo hizo emerger preguntas importantes sobre lo que es una clase y lo que hace a una escuela: ¿es una serie encadenada de tareas? ¿La escuela es un centro de distribución de información y de trabajos escolares, o es otra cosa? ¿Y en qué consisten esos trabajos escolares?

Paradójicamente, con todas las dificultades e improvisaciones, pareciera que las pedagogías de la emergencia están permitiendo evidenciar algo valioso, y quizás bastante inquietante, sobre las lógicas de trabajo en las clases escolares. Entre otros aspectos, aparece de forma muy clara la imbricación entre

Práxis Educativa, Ponta Grossa, v. 15, 2016482, p. 1-16, 2020 Disponível em: <https://www.revistas2.uepg.br/index.php/praxiseducativa $>$ 
las pedagogías y las tecnologías, las formas y los espacios en que se trabaja el tipo de trabajo que se encara, que condicionan las conversaciones que se pueden generar. Esto implica extender esa mirada material que ya se planteó sobre los espacios y tiempos de lo escolar hacia las prácticas de enseñanza en el aula.

Para indagar en las clases en la emergencia, y analizar cómo organizan ciertas formas de trabajo intelectual, tomo los aportes de Anne-Marie Chartier (2002, 2017) y de Anne Barrère (2004, 2018), que buscan poner en valor los "haceres ordinarios", cotidianos, que hacen a la clase, incluso las cosas que parecen más rústicas o más banales. Interesa especialmente el trabajo de Barrère, que ha estudiado la tarea escolar como una actividad que debería contener "un fuerte componente cognitivo" (BARRÈRE, 2004, p. 28). Para ella el trabajo escolar tiene que ver con la manipulación de signos, sobre todo de mensajes escritos, y requiere una buena parte de interpretación, ya sea de las consignas o los marcos de actividades que se proponen. La pedagoga francesa propone una definición sugerente: la tarea escolar es un trabajo-palimpsesto. En tanto palimpsesto, involucra capas o dimensiones distintas:

es un trabajo de comunicación y de relación; es un trabajo de gestión común de un cierto número de eventos puntuales, ligados a la relación y sus avatares; es un trabajo que puede equipararse a un empleo, con sus monotonías, sus rutinas, su aburrimiento; implica también una parte de gestión del tiempo, de organización y planificación; es un trabajo creativo, o al menos debe movilizar algo de la inspiración, la originalidad, lo artesanal. (BARRÈRE, 2018, p. 31-32)

Barrère distingue cuestiones que debe atender la actividad: la organización del grupo y del tiempo, la coordinación de varios planos y funciones en simultáneo, cierto grado de desafío intelectual. También señala que hay tareas simples y hay tareas complejas; recomienda diversificar las tareas, pero sobre todo que no se piensen como actividades para cumplir burocráticamente sino como oportunidades para desarrollar una actividad intelectual (BARRÈRE, 2018). Barrère y Chartier dejan en claro que la clase se sostiene en actividades que contemplan múltiples dimensiones (organizativas, intelectuales, afectivas), y que las actividades no implican necesariamente procesos de conocimiento ricos y desafiantes.

Siguiendo el hilo que proponen estas pedagogas francesas, podría pensarse en las actividades que se están proponiendo hoy en las pedagogías de la emergencia. ¿Qué "coreografías" de la clase organizan los cuestionarios por Whats $A p p$ ? ¿Qué invita o permite hacer a los estudiantes el enviar un video y solicitar comentarios? ¿Qué esfuerzos demandan de docentes y alumnos las tareas escritas? ¿Qué formas de validación propone la elaboración de audios? ¿Qué polivalencias tiene cada una de estas tareas? Quizás esos interrogantes ayuden a definir qué actividades están permitiendo sostener un trabajo con el conocimiento y están promoviendo formas de estudio más interesantes y productivas, y cuáles no.

Lo que evidencia lo sucedido es que la clase no es repartir tareas y corregirlas, sino que implica abrir algunos proyectos de conocimiento entre todos, en un espacio común, y construir condiciones para que cada uno pueda ir apropiándose de esos lenguajes, esas formas de pensar que propone el curriculum escolar, a su propio modo. La clase es un conjunto de interacciones en el que se conversa, se dialoga, se va y se viene por distintos caminos que, al final, tienen que encontrar algún cauce común. Hay que buscar de qué forma se puede sostener esto en las condiciones tecnológicas que existen, muchas veces precarias y heterogéneas. ¿Cómo sostener la conversación en los múltiples hilos de whatsapp, o entre los que se conectan y los que siguen con los impresos? Lo que se está aprendiendo es que esta forma de dar clase en las plataformas es, contrariamente a lo que solía decirse, pesada y lenta,

Práxis Educativa, Ponta Grossa, v. 15, 2016482, p. 1-16, 2020 Disponível em: <https://www.revistas2.uepg.br/index.php/praxiseducativa $>$ 
porque obliga a muchas coordinaciones difíciles de calibrar. Al revés, en la clase presencial hay una economía en los encuentros, en la co-presencia de los cuerpos, las voces y las miradas que es muy importante para la clase, sobre todo en el nivel primario y secundario que requieren de encuentros periódicos, e invitan a empezar a apropiarse de algunos saberes que requieren acompañamiento cercano, adecuaciones y revisiones continuas.

Además de esta concentración en las tareas o actividades como eje de la clase, otra cuestión que se se está viendo con el predominio de Whatsapp y Facebook en la enseñanza es una creciente oralización de los intercambios escolares, sobre todo en los contextos de menos disponibilidad de tecnologías y de falta de apoyos cercanos, que además ponen en evidencia dificultades anteriores que -se teme- pueden operar en la dirección de mayores exclusiones. En esos contextos, la renuncia a la escritura es un modo de acercar la escuela a los modos de habla y vida de los chicos, y de evitar que se profundice la desconexión. Los audios funcionan como un punto de contacto, un modo de encontrarse pese a la distancia, de sostener la conversación de la que se hablaba antes, pero en varios casos habría que alertar sobre la sustitución de otro tipo de trabajos con los materiales de la cultura (textos escritos, imágenes) que también debería hacer la escuela. Sin duda la enseñanza tiene mucho de oral pero, sin negar su importancia, hay que reconocer la importancia de la materialidad de la escritura, que permite ciertas cosas que no se reducen a lo que habilitan los registros orales.

La cuestión del predominio de la oralidad se conecta con tendencias pedagógicas que ya existían antes de la pandemia, pero que quizás el contexto actual pongan más de manifiesto. En investigaciones en clases con medios digitales en Argentina, se pudo observar que una forma dominante de trabajo es la interacción verbal, muchas veces bajo la forma de un debate; hay en algunas clases una invitación a que todos hablen y participen como forma de capturar la atención y sostener el ritmo de la clase. Pero esa participación es considerada o evaluada por algunos docentes en términos de su expresión, y no tanto por su contenido o su forma, es decir, por el uso o desarrollo del lenguaje oral que demuestran o por el tipo de saberes que pueden movilizarse (DUSSEL; FERRANTE; GONZÁLEZ; MONTERO, 2018). Pasados los primeros grados de la escuela primaria, donde la oralidad ya tiene carta de ciudadanía como saber curricular, el trabajo sobre la oralidad en clase en los grados superiores de la escuela primaria y la secundaria en general no se centra en la corrección de las formas del habla ni incita a modos de lenguaje más sofisticados (VÉASE WAQUET, 2013, para un ejemplo distinto). Habría que mirar los vínculos entre esas formas de oralización de la clase y un "pseudoconstructivismo" que invita a los estudiantes a hablar en nombre de sí mismos para apoyar la construcción de una posición personal (en nombre de la auto-estima, la identidad propia u otros ideales pedagógicos) pero que no fomenta o promueve suficientemente una construcción colectiva de los aprendizajes que se sostenga en algunos saberes disciplinares. ${ }^{5}$ También habría que profundizar, en la línea de una antropología político-cultural de las formas pedagógicas, en el vínculo entre esta invitación a tomar la palabra y algunas características de la sociedad argentina que valoran la importancia de argumentar y del debate político, que autorizan una polifonía de voces, aunque después no se siga de

\footnotetext{
${ }^{5}$ Los pedagogos franceses Élisabeth Bautier y Patrick Rayou proveen otro ejemplo de trabajo con la forma debate en la clase, sobre todo teniendo en cuenta las desigualdades en los aprendizajes. Bautier y Rayou realizan la siguiente observación: [el debate así entendido fomenta] "una verdadera inversión de las lógicas escolares: no se trata de elaborar nuevos saberes convocando saberes ya adquiridos y confrontándolos a una nueva situación, sino de avanzar en una 'situación de aprendizaje' a partir de conocimientos, informaciones y experiencias ya presentes (...). Sin duda, puede hacerse una progresión paso a paso hacia una elaboración nueva a partir del debate si el docente tiene un objetivo de conceptualización precisa, si utiliza y 'regula' las controversias entre alumnos que provienen de sus diferencias de conocimientos y experiencias” (BAUTIER; RAYOU, 2009, p. 76).
}

Práxis Educativa, Ponta Grossa, v. 15, 2016482, p. 1-16, 2020 Disponível em: <https://www.revistas2.uepg.br/index.php/praxiseducativa $>$ 
eso una escucha de esas voces y una mayor democracia en el procesamiento de los diferendos (TERÁN, 2003). De un modo más amplio, puede verse en este nuevo lugar de los registros orales grabados cómo se imbrican las plataformas tecnológicas con las pedagogías disponibles, y cómo las interacciones en Whatsapp o Facebook favorecen y despliegan prácticas de enseñanza que ya estaban presentes pero que hoy adquieren otras dimensiones, incluso reemplazando prácticas largamente asentadas en la escuela como el trabajo con lo escrito. El punto no es oponer unas prácticas (orales) a otras (escritas), sino insistir en que todas deben trabajarse para enriquecer las posibilidades expresivas de los estudiantes.

Puede verse, entonces, que las formas y contenidos de la clase se producen en ese entrecruzamiento entre los entornos socio-técnicos que hay disponibles en este contexto, con sus grandes desigualdades, y las pedagogías que se tienen a mano. Queda en evidencia también que una política pública que quiera elaborar mejores propuestas para que los arreglos de la educación remota en la emergencia no reproduzcan o profundicen desigualdades no solamente tiene que ocuparse de la dotación de equipamientos o conectividad, sino que tiene que preocuparse con la formación pedagógica de los docentes, para que la clase funcione como ese encuentro intergeneracional con formas de saberes que permitan producir otras filiaciones con la cultura, y que no se limiten a una inercia burocrática de cumplir con el programa o distribuir tareas.

\title{
¿Qué hacer? “Es preciso soñar”
}

En esta sección final, querría volver a anudar dos citas que aparecieron al comienzo de este artículo, y que habilitan algún impulso hacia adelante a estas notas escritas junto a los acontecimientos. En El tiempo de una tesis, Derrida vuelve al Lenin de la revolución y señala:

\begin{abstract}
Quiero recordar que, a la pregunta “¿Qué hacer?”, a lo que simultáneamente constituye, diría, una pregunta muy vieja, sin duda, sin embargo no tan vieja, pero también una pregunta nuevecita, una pregunta todavía no escuchada, entre otras cosas Lenin contesta, y con precauciones interesantes, “es preciso soñar". (DERRIDA, 1997b, p. 30)
\end{abstract}

Frente al estado del mundo, al nuevo orden o desorden mundial, a la declaración del desajuste o del out-of-joint, dice que hay que mantener "el aplomo", pero también los ojos abiertos de los soñadores.

La crisis de la pandemia ha presentado un escenario sin precedentes. Hay otra frase que se ha repetido en estos días: "Marx dice que las revoluciones son la locomotora de la historia mundial. Pero tal vez [...] las revoluciones son el manotazo hacia el freno de emergencia que da el género humano que viaja en ese tren" (BENJAMIN, 2008, p. 40). Puede ligarse esta idea del freno, de la desaceleración, con el ejercicio colectivo que propuso al comienzo de la pandemia el filósofo y sociólogo francés Bruno Latour: imaginar las medidas de protección para evitar volver al modelo de producción anterior a la crisis (LATOUR, 2020). Sugirió preguntas, entre las que estaban qué actividades de las suspendidas no queremos que vuelvan, y qué transición imaginar para la gente que vive de esas actividades; qué actividades de las suspendidas queremos que se reanuden, y cómo ayudar a que se reanuden. Este momento de desaceleración, de cierre forzado, quizás pueda ser un momento para imaginar otra escuela posible, otras formas de dar clases, otro vínculo con los saberes y la cultura común. Es preciso soñar.

Práxis Educativa, Ponta Grossa, v. 15, 2016482, p. 1-16, 2020 Disponível em: <https://www.revistas2.uepg.br/index.php/praxiseducativa $>$ 
Soñemos, pues, con una escuela que sea el espacio de lo común y también de lo singular. Soñemos con una escuela que asuma la responsabilidad pedagógica de dialogar con su presente, sin mirar al costado sobre las condiciones socio-técnicas en que se inscribe, pero sin sucumbir a los cantos de sirena de las grandes corporaciones tecnológicas. Soñemos con una escuela que promueve una forma de trabajo con los saberes que invita al estudio, a detenerse, a apropiarse a su propio modo de los materiales de la cultura común, que invita a merodear por lo ajeno, que se resiste a la homofilia de ir de lo mismo a lo mismo que incitan las plataformas. Soñemos con una escuela donde las miradas, la co-presencia simultánea de los cuerpos, el tacto y el olor, tienen un valor que no se reemplaza por la eficiencia, y que insiste también en las preguntas por la justicia, el amor, la vida, aunque no tengan utilidad inmediata. Soñemos con una escuela que no sea pantalla, pero que haga pantalla, que permita proyectarse, identificarse, ligarse a otras filiaciones que permitan abrir mundos propios y con otros. Soñemos con una escuela que aprende de lo que estamos viviendo y que busque reparar, como se pueda, hasta donde pueda, las profundas heridas que dejarán estos tiempos dislocados.

\section{Bibliografía citada}

AGAMBEN, G. Requiem por los estudiantes. Blog Artillería Inmanente, 23/05/2020. Disponível em: https://artilleriainmanente.noblogs.org/?p=1514. 2020. Acesso em: 6 jul. 2020.

BARRÈRE, A. Travailler à l'école. Que font les élèves et les enseignants du secondaire? Rennes: Presses Universitaires de Rennes, 2003.

BARRÈRE, A. Retour à l'éducation. Des exercices scolaires éducatifs pour le XXI ${ }^{\mathrm{e}}$ siècle. Plaidoyer pour un nouveau chantier de recherches. Éducation et Sociétés, v. 42, n. 2, p. 69-83, 2018. DOI: https://doi.org/10.3917/es.042.0069

BAUTIER, É.; RAYOU, P. Les inégalités d'apprentissage. Programmes, pratiques et malentendus scolaires. Paris: Presses Universitaires de France, 2009.

BENJAMIN, W. Tesis sobre la historia y otros fragmentos. Traducción e Introducción: Bolívar Echeverría. Ciudad de México: Itaca-Universidad Autónoma de la Ciudad de México, 2008.

BURBULES, N. C. Meanings of ubiquitous learning. In: COPE, B.; KALANTZIS, M. (ed.). Ubiquitous Learning. Urbana: University of Illinois Press, 2009. p. 15-20.

CASTRO, E. El vocabulario de Michel Foucault. Un recorrido por sus temas, conceptos y autores. Buenos Aires: Prometeo/Universidad Nacional de Quilmes, 2004.

CHARTIER, A-M. Um dispositivo sem autor: cadernos e fichários na escola primária. Revista Brasileira de História da Educação, v. 2, n. 1 [3], p. 9-26, 2002.

CHARTIER, A-M. Former des enseignants avec (et malgré?) la recherche. Entretien avec Anne Barrère, Recherche et formation, v. 85, p. 81-92, 2017. Disponível em: http://journals.openedition.org/rechercheformation/2879. Acesso em: 30 jul. 2020.

CHUN, W. Queering Homophily. In: APPRICH, C.; CHUN, W.; CRAMER, F.; STEYERL, H. Pattern discrimination. Minneapolis: University of Minnesota Press-Meson Press, 2018. p. 59-97. 
DERRIDA, J. Espectros de Marx. El estado de la deuda, el trabajo de duelo y la nueva internacional. Madrid: Editorial Trotta, 1992.

DERRIDA, J. Mal de archivo. Una impresión freudiana. Madrid: Editorial Trotta. 1997a.

DERRIDA, J. El tiempo de una tesis. Desconstrucción e implicaciones conceptuales. Barcelona: Proyecto A Ediciones, 1997b.

DIJCK, J. VAN. La cultura de la conectividad. Una historia crítica de las redes sociales. Buenos Aires: Siglo XXI editores, 2016.

DIJCK, J. VAN.; POELL, T. Social Media Platforms and Education. In: BURGESS, J.; MARWICK, A.; POELL, T. (ed.). The SAGE Handbook of Social Media. London: SAGE Publishing, 2018. p. 579-591.

DUSSEL, I. Atención y trabajo escolar en las aulas conectadas, más allá de la pandemia. Le Monde Diplomatique, 2020 (no prelo).

DUSSEL, I. The Digital Classroom: A Historical Consideration on the Redesigning of the Contexts of Learning. In: GROSVENOR, I.; RASMUSSEN, L. R. (ed.). Making Education: Material School Design and Educational Governance. Cham: Springer International Publishing, 2018. p. 173-196.

DUSSEL, I.; CARUSO, M. La invención del aula. Una genealogía de las formas de enseñar. Buenos Aires: Editorial Santillana, 2000.

DUSSEL, I.; FERRANTE, P.; GONZÁLEZ, D.; MONTERO, J. Las pedagogías en movimiento. Usos y apropiaciones de las tecnologías digitales por parte de docentes y alumnos en escuelas secundarias públicas bonaerenses. In: PEREYRA, A.; PASIN, J. (ed.). Las TIC en la escuela secundaria bonaerense. Usos y representaciones en la actividad pedagógica. Buenos Aires, UNIPE: Editorial Universitaria, 2018. p. 81-125.

DUSSEL, I.; FERRANTE, P., PULFER, D. (eds). Pensar la educación en la pandemia. Entre la emergencia, el compromiso y la espera. Buenos Aires, UNIPE: Editorial Universitaria (no prelo).

FOUCAULT, M. El orden del discurso. Barcelona: Tusquets, 1973.

FOUCAULT, M. Vigilar y castigar. El nacimiento de la prisión. México: Siglo XXI Editores, 1976.

FOUCAULT, M. Espacios Otros. Versión. Estudios de Comunicación y Cultura, v. 9, p. 15-26, 1999.

GITELMAN, L. Paper knowledge. Toward a media history of documents. Durham and London: Duke University Press, 2014.

HODGES, C. H.; MOORE, S.; LOCKEE, B.; TRUST, T.; BOND, M. A. The Difference Between Emergency Remote Teaching and Online Learning. EDUCAUSE Review, March 27 2020. Disponível em: https://er.educause.edu/articles/2020/3/the-difference-between-emergency-remoteteaching-and-online-learning. Acesso em: 26 mayo 2020.

LATOUR, B. ¿Qué medidas de protección para evitar el regreso del modelo de producción de la precrisis? [Imaginer les gestes-barrières contre le retour à la production d'avant crise]. AOC media

Práxis Educativa, Ponta Grossa, v. 15, 2016482, p. 1-16, 2020 Disponível em: < https://www.revistas2.uepg.br/index.php/praxiseducativa $>$ 
[Analyse Opinion Critique]. 30 mar. 2020. Disponível em: https://aoc.media/opinion/2020/03/29/imaginer-les-gestes-barrieres-contre-le-retour-a-laproduction-davant-crise/. Acesso em: 6 jul. 2020.

LATOUR, B. Reensamblar lo social. Una introducción a la teoría del actor en red. Buenos Aires: Manantial, 2005.

MAILLARD, C. H. India. Obras reunidas. Ed: Antonio Rodríguez Esteban. Valencia: Pre-Textos, 2014.

MASSCHELEIN, J. Making the school: stories of caves and tables. In: LAMBRECHT, W.; VANSIELEGHEM, N. (ed.). Old School/Nieuwe Klas. Ghent: LUCA School for the Arts, 2014. p. 43-53.

PINEAU, P. Esas fotocopias grises y manchadas: Tecnología y universidad en un contexto de masividad. Módulo 1, Curso Virtual de Posgrado: Enseñanza Mediada por Tecnologías, Universidad Nacional de José C. Paz, 2020.

PINEAU, P. ¿Por qué triunfó la escuela?, o la modernidad dijo: 'Esto es educación' y la escuela respondió: 'Yo me ocupo'. In: PINEAU, P.; DUSSEL, I.; CARUSO, M. La escuela como máquina de educar. Buenos Aires: Paidós, 2001. p. 27-52.

QUEZADA, R. Latin American National Responses to COVID-19 in Digital Learning: Current Trends and Future Impact. 2020. Institute of Latin American Studies-Columbia University. Disponível em: http://ilas.columbia.edu/covid-19-impacts/. Acesso em: 13 mayo 2020.

RANCIÈRE, J. El espectador emancipado. Buenos Aires: Manantial, 2009.

REVEL, J. Michel Foucault: repenser la technique. Tracés, n. 16, p. 139-149, mayo 2009. DOI: https://doi.org/10.4000/traces.2583

RIOUX, C. H. Assignés à résidence. Les Mureaux. Février 2018-Mai 2020. Tracts de Crise Gallimard, n. 66, 2020.

SADOVSKY, P.; LERNER, D. (coord.). Proyecto: ¿Qué se enseña y qué se aprende en las escuelas de la Ciudad de Buenos Aires? Informe final. Gobierno de la Ciudad de Buenos Aires, Secretaría de Educación, Dirección de Investigaciones Educativas, 2006.

SEBESTYEN, V. Lenin. Una biografía. Barcelona: Ático de los libros, 2020.

SIMONS, M.; MASSCHELEIN, J. En defensa de la escuela. Una cuestión pública. Buenos Aires: Miño y Dávila Editores, 2014.

TONUCCI, F. No perdamos este tiempo precioso dando deberes. Diario E1 País, 11 de abril de 2020. Disponível em: https://elpais.com/sociedad/2020-04-11/francesco-tonucci-no-perdamos-estetiempo-precioso-dando-deberes.html. Acesso em: 6 jul. 2020.

UNICEF Argentina. Encuesta Covid-19. Percepciones y actitudes de la población. Impacto de la pandemia en hogares con niños, niñas y adolescentes. Mayo 2020. Informe Sectorial Educación. 
Disponível em: https://www.unicef.org/argentina/media/8056/file/Covid19-EncuestaRapidaInformeEducacion.pdf. Acesso em: 6 jul. 2020.

TERÁN, O. La Experiencia de la crisis. Punto de Vista, Buenos Aires, n. 73, p.1-3, 2002.

WAQUET, F. "La part discrète de la philosophie": de maître à élève dans les lycées français. In: Névot, A. (ed.). De l'un à l'autre. Maîtres et disciples. Paris: CNRS Éditions, 2013. p. 87-113.

WILLIAMSON, B.; ENYON, R.; POTTER, J. Pandemic politics, pedagogies and practices: digital technologies and distance education during the coronavirus emergency. Learning, Media and Technology, v. 45, n. 2, p. 107-114, 2020. DOI: https://doi.org/10.1080/17439884.2020.1761641

ZIMMERMAN, J. Coronavirus and the Great Online-Learning Experiment. Chronicle of Higher Education, march 10, 2020. Disponível em: https://www.chronicle.com/article/ coronavirus-and-the-great-online-learning-experiment/. Acesso em: 6 jul. 2020.

Recibido: $30 / 06 / 2020$

Aceptado: 29/07/2020

Publicado online: $01 / 08 / 2020$

Práxis Educativa, Ponta Grossa, v. 15, 2016482, p. 1-16, 2020 